\section{Severe pancreatitis following hot-snare polyp- ectomy of a distal biliary inflammatory polyp during ERCP in a heart transplant recipient}

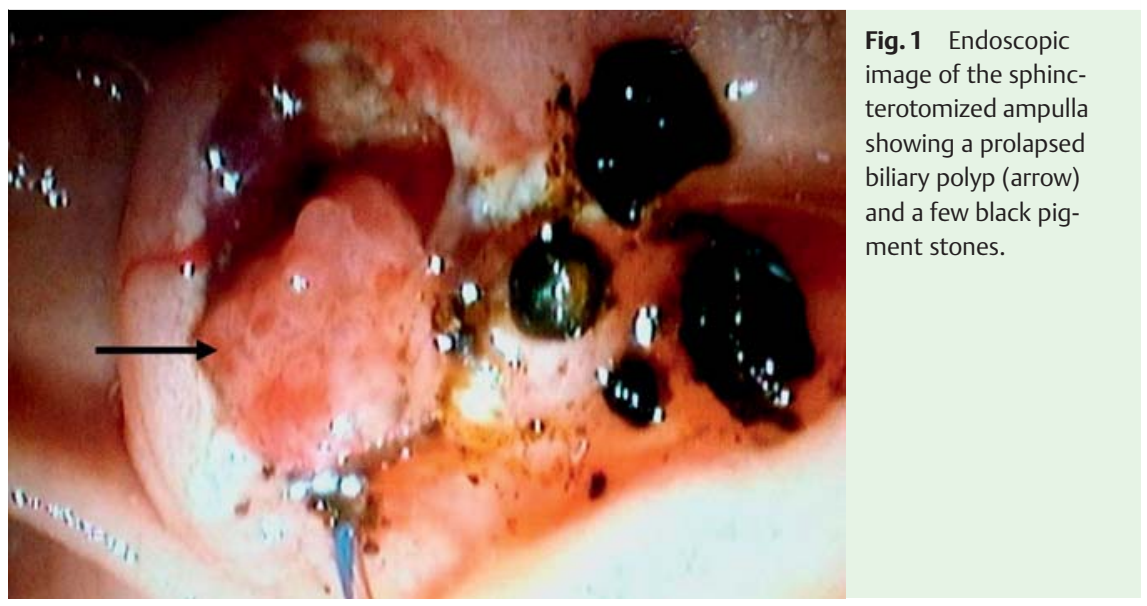

Biliary polyps are rare and have never been described in transplant recipients. Herein, we describe a heart transplant recipient with a distal biliary polyp that was causing biliary obstruction who developed severe pancreatitis following endoscopic polypectomy, a complication previously unreported.

A 65-year-old heart transplant recipient for stage 4 congestive heart failure presented with 4 days of epigastric pain and vomiting. Examination was unremarkable. Investigations revealed bilirubin $18.6 \mu \mathrm{mol} / \mathrm{L}$, alkaline phosphatase (ALP) $155 \mathrm{U} / \mathrm{L}, \quad \gamma$-glutamyltransferase (GGT) $183 \mathrm{U} / \mathrm{L}, \mathrm{C}$-reactive protein (CRP) $225 \mathrm{mg} / \mathrm{L}$ and normal amylase. Magnetic resonance cholangiopancreatography (MRCP) showed cholelithiasis and choledocholithiasis with biliary dilatation.

An endoscopic retrograde cholangiopancreatography (ERCP) was performed, during which selective biliary cannulation was achieved without prior pancreatic duct cannulation or contrast injection. Biliary stones were confirmed and biliary sphincterotomy was performed. Following complete stone extraction, a 5-mm distal common bile duct polyp prolapsed out of the sphincterotomized ampulla ( $\bullet$ Fig. 1$)$. Given the risk for further biliary obstruction, snare polypectomy was performed using a coagulation current of $30 \mathrm{~W}$. Histology subsequently revealed an inflammatory polyp.

Following ERCP, the patient developed clinical, biochemical, and radiological evidence of acute pancreatitis (amylase $3161 \mathrm{U} / \mathrm{L})$, which was complicated by intra-abdominal compartment syndrome, respiratory failure, and renal failure, and required intensive care management for noninvasive ventilation and hemofiltration. He made a successful recovery after a few days. Laparoscopic cholecystectomy was performed 3 months later.

Various risk factors, both patient and procedure related, predispose to post-ERCP pancreatitis (PEP) [1]. Hot-snare polypectomy of distal biliary polyps, however, has not yet been proposed as a risk factor for PEP. Intraductal biliary polypectomy using a choledochoscope seems safe [2]. Herein, we speculate that severe pancreatitis occurred because the polypectomy was performed at the level of the papilla, with this being similar to the pancreatitis that is seen after endoscopic ampullectomy [3]. To our knowledge, this is the first case report of a biliary polyp in a solid-organ transplant recipient being complicated by pancreatitis post-distal biliary polypectomy. We propose that this should be a new risk factor for PEP.

Endoscopy_UCTN_Code_CPL_1AK_2AB

Competing interests: None

\section{Jurgen Gerada, Ramona Camilleri, James Pocock}

Division of Gastroenterology, Mater Dei Hospital, Msida, Malta

\section{References}

1 Dumonceau JM, Andriulli A, Joseph Elmunzer $B$ et al. Prophylaxis of post-ERCP pancreatitis. European Society of Gastrointestinal Endoscopy (ESGE) Guideline - Updated June 2014. Endoscopy 2014; 46: 799-815

2 Rafiq E, Alaradi O, Bawany $M$ et al. A combination of snare polypectomy and apc therapy for prolapsing common bile duct adenoma. J Interv Gastroenterol 2012; 2: $193-$ 195

3 Patel R, Varadarajulu S, Wilcox CM. Endoscopic ampullectomy: techniques and outcomes. J Clin Gastroenterol 2012; 46: 8-15

\section{Bibliography}

DOI http://dx.doi.org/

10.1055/s-0034-1391132

Endoscopy 2015; 47: E63

(c) Georg Thieme Verlag KG Stuttgart $\cdot$ New York

ISSN 0013-726X

\section{Corresponding author}

Jurgen Gerada, MD, MSc

Mater Dei Hospital

Msida

Malta

Fax: +356-254-57582

jurgen.gerada@gmail.com 